www.jmscr.igmpublication.org

Impact Factor 5.84

Index Copernicus Value: 83.27

ISSN (e)-2347-176x ISSN (p) 2455-0450

crossref DOI: _https://dx.doi.org/10.18535/jmscr/v5i7.129

Journal Of Medical Science And Clinical Research

IGM Publication

An Official Publication of IGM Publication

\title{
Frequency of Rh Phenotypes in Voluntary Blood Donors
}

\author{
Authors \\ Dr Rashi Pachaury ${ }^{1}$, Dev Raj Arya ${ }^{2}$, Novrang Lal Mahawar ${ }^{3}$, Arun Bharti ${ }^{4}$, \\ Pankaj Kumar Das ${ }^{5}$ \\ ${ }^{1}$ Resident, Department of IHBT, S.P Medical College, Bikaner, Rajasthan \\ Email: pachaury.rashi@gmail.com \\ ${ }^{2}$ Senior Professor and Head, Department of IHBT, S.P Medical College, Bikaner, Rajasthan \\ ${ }^{3}$ Associate Professor, Department of IHBT, S.P Medical College, Bikaner, Rajasthan \\ ${ }^{4}$ Assistant Professor, Department of IHBT, S.P Medical College, Bikaner, Rajasthan \\ ${ }^{5}$ Resident, Department of IHBT, S.P Medical College, Bikaner, Rajasthan
}

\begin{abstract}
Background: Very few reports are available regarding Rh phenotypes prevalence in India and no reports are available from Rajasthan. There is a possibility of alloimmunization and antibody production in the recipients, even after proper grouping and cross matching. Due to the heavy financial burden of complete phenotyping; the knowledge of Rh phenotypes can play a major role in preventing alloimmunization. The aim of this study to prevalence of principal Rh blood group antigens like $D, C, E, c$ \& $e$ in the voluntary blood donors with a view to generate blood bank data for constitution of panel of blood donors for multipurpose utilities.

Materials and Methods: A prospective study was carried out on 3014 healthy blood donors from April 2016 to Nov 2016 at our blood bank. Donors were grouped and typed for ABO and Rh major antigens. Statistical analysis was carried out using Microsoft excel software. Incidence was given in proportion with 95\% confidence interval. Allele frequencies were also calculated using Hardy-Weinberg principal.

Results: Among Rh antigens, e was the most common antigen (98.71\%), followed by D-91.94\%, C-81.85\%, c-62.77\% and E-17.25\% with DCe/DCe (RIR1) (36.43\%) being the most common phenotype and the least common phenotype is r' $r$ ', $r$ " $r$ ", $r$ 'r" $(0.03 \%)$.

Conclusion: Determination of Rh phenotypes can play a major role in preventing alloimmunization in multi-transfusion cases. Database for antigen frequency to at least Rh blood group system in local donor population helps to provide antigen negative blood unit to patients with multiple alloantibodies, minimize alloimmunization rate, there by improve blood safety.

Keywords: Rh blood group antigens, Rh phenotypes, Allele, Prevalence, Alloimmunization
\end{abstract}

\section{Introduction}

The primary goal of any blood transfusion is to provide the patient, donor red blood cells with optimal intravascular survival after transfusion and serve their function. The criteria for selection of donor cells focuses on absence of antigens on donor cells against that antibodies are detected in the patient's serum in need of transfusion. ${ }^{1}$

India is a vast country with several distinct population groups, so there is an obvious need for 
phenotype frequencies to be determined in different parts of India. The data on incidence of antigens of various blood groups in the local donor population helps in routine blood transfusion practices of a blood transfusion centre. ${ }^{2}$ In situations where clinically significant antibodies are identified in patient's serum, antigen-negative donor units for such cases can be easily retrieved from the donor database of various blood groups available with a blood transfusion centre. For this particular reason, all blood banks should have the donor database on antigen frequency of other blood group systems in their local donor population.

Very few studies regarding the incidence of various blood groups in the blood donor population are published from India. ${ }^{3,4}$ Blood transfusion can cause immediate or delayed immunological reactions, out of these most serious is the hemolytic transfusion reaction by antibody incompatibility.

A total of $308 \mathrm{RBC}$ antigens are recognized till now by the International Society of Blood Transfusion (ISBT), 270 of which are clustered in 30 blood group systems. ${ }^{5}$ The Rh blood group system (including the $\mathrm{Rh}$ factor) is one of thirtyfive current human blood group systems. It is the second most important blood group system, after $\mathrm{ABO}$ and consists of 50 defined bloodgroup antigens, among which the five antigens D, $\mathrm{C}, \mathrm{c}, \mathrm{E}$, and e are the most important. The main antigens are D, C, E, c and e, which are encoded by two adjacent gene loci, the RHD gene which encodes the $\mathrm{RhD}$ protein with the $\mathrm{D}$ antigen (and variants) ${ }^{6}$ and the RHCE gene which encodes the RhCE protein with the $\mathrm{C}, \mathrm{E}, \mathrm{c}$ and e antigens (and variants). ${ }^{7}$ There is no $d$ antigen. Lowercase "d" indicates the absence of the D antigen (the gene is usually deleted or otherwise nonfunctional).

Retrospective studies in the general population reported antibody frequencies after transfusion in less than 1 to 3 percent. However, in multitransfused patients, alloimmunizaton occurs in up to $70 \%$ of patients. ${ }^{8,9}$ In countries where phenotyping is mandatory (eg. in France since
2002) in all donated blood and in recipients, posttransfusion alloimmunization have become rare. ${ }^{10}$ Some developed countries have already made revolutionary changes in their cross match protocols and have started complete genotyping of their donors to make a huge database of donors for future usage and references. Some other countries have made extensive phenotyping and complete cross matching compulsory for the category of patients who may require multiple transfusions in future. These procedures have added massively to the cost of blood banking in developed nations and thus its implementation in developing countries like India is way behind. ${ }^{11}$ Keeping in view the heavy financial burden of complete phenotyping of blood; the determination of only $\mathrm{Rh}$ phenotypes can play a major role in preventing alloimmunization in multi-transfusion cases. The current practice of providing compatible blood to patients in such cases in India is still reliant upon random cross matching of available units in the inventory. There is wide variation in distribution and frequency of $\mathrm{Rh}$ antigens throughout the world and lack of study especially from west part of India i.e. in the population of Rajasthan, impelled us to identify the frequency of five major $\mathrm{Rh}$ antigens and its phenotype. This study was carried out to determine the phenotypic frequency of various $\mathrm{Rh}$ antigens $(\mathrm{D}, \mathrm{C}, \mathrm{E}, \mathrm{c}, \mathrm{e})$ in healthy blood donors and to generate blood bank data for constitution of panel of blood donors for multipurpose utilities.

\section{Materials and Methods}

A total of 3014 samples from random voluntary blood donors coming in blood donation camp organized by the Department of IHBT, S.P. Medical College and Associated group of Hospital, Bikaner, were collected for extended antigen typing during April 2016 to November 2016 after obtaining approval from the Institutional ethical committee. Written consent was taken at the time of donor screening. Collected blood samples were from VBD camps organized in different areas so that we have 
representative samples in the study from urban and rural areas of different zones of Rajasthan, India.

The D, C, c, E, e antigens were typed using monoclonal antisera from Immucor derived from clones D175-2/TH28, MS24, MS33, MS258+MS80 and MS16+MS21 respectively. Donors typed as D negative were confirmed using an antiglobulin weak D test by tube method using commercially available antisera [Novaclone antiD (Immucor Rodermark, Germany) which contains IgG clone D415 in addition to IgM clone D175-2.]

Before proceeding to extended Rh phenotyping, the donor's $\mathrm{ABO}$ grouping was done. For Rh antigens (D, C, c, E, and e), red blood cells were tested against specific antisera to observe antigenantibody reactions (haemagglutination) by the microplate haemagglutination method with $\operatorname{IgM}$ monoclonal antiserum on a fully automated system (Galileo, Neo, Immucor Inc., Norcross, GA, USA) as per instructions provided in the instrument operator manual. Conventional tube method was also done using 1 drop of specific antisera with 1 drop of $3-4 \%$ suspension of red blood cells to be tested. No agglutination indicated its absence. Agglutination reactions in positive test results were recorded and graded as $1+$ to $4+$. All samples that showed a negative agglutination with anti-D were tested again in the antihuman globulin phase with monoclonal antisera (Blend $\operatorname{IgG}+\operatorname{IgM}$ ) by tube technique for the presence of weak " $D$ " as per the manufacturer's instructions.

Statistical analysis was done by Calculation of red cell antigen and phenotype frequencies of the various blood group systems by totalling the number of donors positive for a particular antigen phenotype divided by the total number of donors screened. Results were expressed as a percentage. Statistical analysis was done using Microsoft office Excel software. Allele frequencies were calculated under the standard assumption of Hardy-Weinberg equilibrium. Incidence was given in proportion with $95 \%$ confidence interval.

\section{Results}

During the study period, antigen typing was done on 3014 voluntary blood donors. ABO grouping in this study showed that " $\mathrm{B}$ " was the most common blood group (37.92\%) followed by "O" (32.25\%), "A" (20.97\%) and "AB" was the least common $(8.86 \%)$ type. $\mathrm{RhD}$ typing along with other major $\mathrm{Rh}$ antigens was done on all the donors and out of the 3,014 donors 2,771 (91.94\%) were D positive and $243(8.06 \%)$ were $\mathrm{D}$ negative (Table 1). shows the distribution of $\mathrm{Rh}$ $(\mathrm{C}, \mathrm{E}, \mathrm{c}, \mathrm{e})$ antigens in the study population. Among the five major antigens, "e" antigen was found to be the most common antigen $(98.71 \%$ ) followed by "C" (81.85\%), "c" (62.77\%) and "E" being least common antigen (17.25\%). Blood group wise distribution of $\mathrm{Rh}$ principal antigens is shown in (Table 2). There was no difference in distribution of $\mathrm{Rh}$ antigens irrespective of their blood group. Allele frequency is shown in the Figure 1. Antigen frequency (AF) of other $\mathrm{Rh}$ antigens in $\mathrm{Rh}$ (D) positive and $\mathrm{Rh}$ (D) negative blood donors in the study population is shown in (Table 3). The maximum antigen frequency in $\mathrm{Rh}$ (D) positive donors was e (98.63\%) followed by $\mathrm{C}$ $(88.42 \%)$ and in $\mathrm{Rh}$ (D) negative donors e $(99.59 \%)$ followed by c $(97.53 \%)$. Since genotyping was not done, the presumed $\mathrm{Rh}$ phenotype frequencies in our population are shown in (Table 4). The most common phenotype observed was $R_{1} R_{1}$ (DCCee) followed by $R_{1} r$ (DCcee) $>R_{1} R_{2}(D C c E e)>\operatorname{rr}(d c e)>R_{2} r(D c c E e)$ and the least common being r' r, r"r" and r'r" among the total study population. Most common phenotype in $\mathrm{Rh}$ positives was $\mathrm{R}_{1} \mathrm{R}_{1}$ and among $\mathrm{Rh}$ negatives was rr. 
Table 1. Prevalence of other Rh blood group antigens in the study population

\begin{tabular}{|l|c|c|c|}
\hline Antigen & No. $(\mathrm{n}=3014)$ & Percentage (\%) & $95 \%$ CI \\
\hline C & 2467 & 81.85 & $80.47-83.23$ \\
\hline c & 1892 & 62.77 & $61.04-64.5$ \\
\hline E & 520 & 17.25 & $15.9-18.6$ \\
\hline e & 2975 & 98.71 & $98.31-99.11$ \\
\hline
\end{tabular}

Table 2. Prevalence of Rh blood group Antigens in ABO Blood group system.in the study population

\begin{tabular}{|l|c|c|c|c|c|}
\hline \multirow{2}{*}{ Blood Group } & \multicolumn{5}{|c|}{ Rh antigens } \\
\cline { 2 - 6 } & $\mathrm{D} \%$ & $\mathrm{C} \%$ & $\mathrm{c} \%$ & $\mathrm{E} \%$ & $\mathrm{e} \%$ \\
\hline A (n=632) & $92.25 \%$ & $83.23 \%$ & $64.40 \%$ & $18.20 \%$ & $99.05 \%$ \\
\hline B (n=1143) & $91.60 \%$ & $80.66 \%$ & $61.94 \%$ & $17.41 \%$ & $98.51 \%$ \\
\hline O (n=972) & $92.18 \%$ & $82.30 \%$ & $63.68 \%$ & $17.28 \%$ & $98.77 \%$ \\
\hline AB (n=267) & $91.76 \%$ & $82.02 \%$ & $59.18 \%$ & $14.23 \%$ & $98.50 \%$ \\
\hline
\end{tabular}

Table 3. Prevalence of other Rh blood group Antigens in $\mathrm{Rh}(\mathrm{D})$ positive and $\mathrm{Rh}$ (D) negative blood donors in the study population

\begin{tabular}{|l|c|c|c|c|}
\hline \multirow{2}{*}{ Total no. of donors } & \multicolumn{4}{|c|}{ Antigen frequency (\%) } \\
\cline { 2 - 5 } & $\mathrm{C}$ & $\mathrm{c}$ & $\mathrm{E}$ & $\mathrm{e}$ \\
\hline D positive (2771) & 88.42 & 59.73 & 18.62 & 98.63 \\
\hline D negative (243) & 7.00 & 97.53 & 1.65 & 99.59 \\
\hline
\end{tabular}

Table 4. Frequency of various Rh Phenotypes in study population

\begin{tabular}{|c|c|c|c|}
\hline Rh Phenotypes & Frequency & Percentage & $95 \% \mathrm{CI}$ \\
\hline CCDee $\left(R_{1} R_{1}\right)$ & 1098 & 36.43 & $34.71-38.15$ \\
\hline $\operatorname{ccDEE}\left(\mathrm{R}_{2} \mathrm{R}_{2}\right)$ & 36 & 1.19 & $0.8-1.58$ \\
\hline CcDee $\left(\mathrm{R}_{1} \mathrm{r}\right)$ & 1056 & 35.04 & $33.34-36.74$ \\
\hline ccDEe $\left(\mathrm{R}_{2} \mathrm{r}\right)$ & 186 & 6.17 & $5.31-7.03$ \\
\hline ccDee $\left(\mathrm{R}_{0} \mathrm{r}\right)$ & 98 & 3.25 & $2.62-3.88$ \\
\hline $\operatorname{CCDEE}\left(\mathrm{R}_{\mathrm{Z}} \mathrm{R}_{\mathrm{Z}}\right)$ & - & - & - \\
\hline CCDEe $\left(\mathrm{R}_{1} \mathrm{R}_{\mathrm{Z}}\right)$ & 15 & 0.50 & $0.25-0.75$ \\
\hline $\operatorname{CcDEE}\left(\mathrm{R}_{2} \mathrm{R}_{\mathrm{Z}}\right)$ & 2 & 0.07 & * \\
\hline CcDEe $\left(R_{1} R_{Z}\right)$ & 279 & 9.26 & $8.23-10.29$ \\
\hline Ccdee (r'r) & 11 & 0.36 & $0.15-0.57$ \\
\hline CCdee (r'r') & 5 & 0.17 & $0.02-0.32$ \\
\hline ccdEe (r"r) & 1 & 0.03 & $*$ \\
\hline ccdEE (r"r") & 1 & 0.03 & $*$ \\
\hline ccdee (rr) & 223 & 7.40 & $6.47-8.33$ \\
\hline CcdEe (r'r") & 1 & 0.03 & $*$ \\
\hline D--ee & 1 & 0.03 & * \\
\hline d--Ee & 1 & 0.03 & $*$ \\
\hline
\end{tabular}


Table 5. Comparison of prevalence of other Rh antigens with other Indian and worldwide studies

\begin{tabular}{|l|c|c|c|c|}
\hline Indian Studies & C & c & E & E \\
\hline Thakral et al.[3] & 84.8 & 52.8 & 17.9 & 98.3 \\
\hline Sarkar et al.[11] & 87.55 & 51.06 & 26.55 & 98.42 \\
\hline Sharma et al.[12] & 84 & 58.3 & 25.6 & 78.5 \\
\hline Makroo et al.[13] & 87 & 58 & 20 & 98 \\
\hline D. Lamba et al.[14] & 85.1 & 62.3 & 21.5 & 99.0 \\
\hline World Population & 68 & 80 & 29 & 98 \\
\hline Caucasians[2,15,16] & 27 & 96 & 22 & 98 \\
\hline Blacks[2,15,16] & 68 & 80 & 29 & 98 \\
\hline Whites[2,15,16] & 93 & 47 & 39 & 96 \\
\hline Chinese[17] & 81.85 & 62.77 & 17.25 & 98.71 \\
\hline Present Study & &
\end{tabular}

\section{Discussion}

In Rhesus system our study shows frequency of Rh positive was $91.94 \%$, while only $8.06 \%$ was $\mathrm{Rh}$ negative. These figures are similar to the other studies carried out in different parts of India. ${ }^{3,11}$ The prevalence of other Rh Antigens (C, c, E, e) among the study population was compared with that of other studies carried out in India at different regions $s^{3,11-14}$ and with other populations ${ }^{2,15-17}$ as presented in (Table 5).

Out of 3014 voluntary blood donors in present study the most common phenotype was found to be $\mathrm{R}_{1} \mathrm{R}_{1}(36.43 \%)$ followed by $\mathrm{R}_{1} \mathrm{r}(35.03 \%)$. In our study most common phenotype among $\mathrm{Rh}$ positives $(n=2771)$ is $R_{1} R_{1}$ with $39.62 \%$ and the least common phenotype is $\mathrm{R}_{2} \mathrm{R}_{\mathrm{Z}}$ with $0.07 \%$. Among $\mathrm{Rh}$ negatives $(\mathrm{n}=243)$, most common phenotype is rr with a frequency of $91.77 \%$ and the least common is r"r, r"r" and r'r" with $0.41 \%$. No sample of $\mathrm{Rh}_{\text {null }}$ was reported in present study while in 2 samples $(0.07 \%)$ deletion of antithetical antigen $\mathrm{C} / \mathrm{c}$ was found i.e. 1 case of $\mathrm{D}$--ee and 1 case of d--Ee). Rare blood is defined, on the basis of the blood group characteristics, as being found at a frequency of $\leq 1: 1000$ random samples in a given population. ${ }^{18,19}$ The $\mathrm{Rh}$ phenotype $\mathrm{R}_{2} \mathrm{R}_{\mathrm{Z}}, \mathrm{r}$ r, $r " r "$ and r'r" were found to be rare in our population with percentage prevalence of 0.07 , $0.03,0.03$ and 0.03 , respectively. Weak D phenotype was not observed in our study.

On comparing the $\mathrm{Rh}$ phenotype distributions among international studies, significant differences were found. In blacks, most common $\mathrm{Rh}$ phenotype is $\mathrm{R}_{0} \mathrm{r}(45.8 \%)$ and the least common is $\mathrm{R}_{2} \mathrm{R}_{2}$ with $0.2 \%$. In Caucasians most and least common $\mathrm{Rh}$ Phenotype is $\mathrm{R}_{1} \mathrm{r} \& \mathrm{R}_{\mathrm{Z}} \mathrm{R}_{\mathrm{Z}}$ with $35.6 \%$ and $0.0004 \%$ respectively. ${ }^{2,15,16}$

\section{Conclusion}

There is wide range of distinctions in phenotypes and probable genotypes among different races and religion. Our study concluded that most frequent antigen amongst five major antigens of Rh system was Rh "e" (98.71\%) whereas the least common was antigen "E" (17.25\%). DCCee was the most common phenotype. The most frequent probable genotype was DCe/DCe $\left(\mathrm{R}_{1} \mathrm{R}_{1}\right)$ among $\mathrm{Rh}$ positives whereas among $\mathrm{Rh}$ negatives it was dce/dce (rr).

Outcomes of such studies can be used to formulate a Rare Blood group Donor registry (donors lacking high frequency antigens) at national level, and patients with antibodies against high frequency antigens can be directed to such Rare Blood Group donor registry.

Though the sample size of this study was relatively small compared to the huge population of the country, it still gives an estimate of the frequencies of $\mathrm{Rh}$ blood group antigens The gene pool of people from other parts like South/ East/ North India may be somewhat different from that of the West Indians and thus a multi-centric study in hospitals located in different regions, would be valuable to provide information regarding the frequencies of the various antigens in different regions of India. 


\section{References}

1. Chapman JF, Elliott C, Knowles SM, Milkins CE, Poole GD. Guidelines for compatibility procedures in blood transfusion laboratories. Transfus Med. 2004;14:59-73.

2. Brecher ME. 15th ed. Bethesda: American Association of Blood Banks; 2005. Technical manual; pp. 304-58.

3. Thakral B, Saluja K, Sharma RR, Marwaha N. Phenotype frequencies of blood groups systems (Rh, Kell, Kidd, Duffy, MNS, P, Lewis, and Lutheran ) in north Indian blood donors. Transfus Apher Sci.2010;43:17-22. [PubMed]

4. Nanu A, Thapliyal RM. Blood group gene frequency in a selected north Indian population. Indian J Med Res. 1997;106:242-6. [PubMed]

5. Daniels G, Castilho L, Flegel WA, Fletcher A, Garratty G, et al. International Society of Blood Transfusion Committee of terminology for red blood cell surface antigens: Macao report. Vox Sang, (2009);96: 153-156.

6. "RHCE $\mathrm{Rh}$ blood group, CcEe antigens [Homo sapiens] - Gene Result". nlm.nih.gov. Retrieved 2010-06-15.

7. Rosenfield RE, Allen FH Jr., Rubinstein P. Genetic model for the $\mathrm{Rh}$ blood-group system. Proc Natl Acad Sci U S A. 1973;70:1303-1307.

8. Zalpuri S, Zwaginga JJ, Le Cessie S et al. Red-blood- cell alloimmunization and number of red-blood- cell transfusions. Vos Sanguinis 2012; 102:144-149.

9. Miller ST, Kim HY, Weiner DL, et al. Investigators of the Sickle Cell Disease Clinical Research Network (SCDCRN). Red blood cell alloimmunization in sickle cell disease: prevalence in 2010. Transfusion 2013; 53:704-709.

10. Padaro E, Kueviakoe IM, Agbétiafa K et al. Phénotypage érythrocytaire et recherche des agglutinines irrégulières chez les drépanocytaires majeurs : à propos de 109 cas colliges au CHU Campus de Lomé (Togo) de mai à décembre 2003. J. Rech. Sci. Univ. Lomé 2011; 13:193-198.

11. Sarkar RS, Philip J, Mallhi RS, Yadav P. Proportion of $\mathrm{Rh}$ phenotypes in voluntary blood donors. Med J Armed Forces India. 2013; 69(4):330-4.

12. Sharma dc, Singhal S, Rai S, Iyenger S, Sao $S$ and Jain B. Incidence of $R h$ antigens, phenotype \& probable genotype in the population of Gwalior and Chambal region, Central India. Int Blood Res Rev. 2013;1:29-43.

13. R.N.Makroo, Aakanksha Bhatia, Richa Gupta \& Jessy Phillip; Prevalence of Rh, Duffy, Kell, Kidd \& MNSs blood group antigens in the Indian blood donor population: Indian J Med Res 137, March 2013, pp 521-526.

14. Divjot Singh Lamba, Ravneet Kaur, and Sabita Basu: Clinically Significant Minor Blood Group Antigens amongst North Indian Donor Population; Advances in Hematology, 2013, Volume 2013, Article ID 215454, 5 pages.

15. Daniels GL. Human Blood Groups. 2nd ed. 2002: Blackwell Science.

16. Reid ME, Lomas-Francis C. 2nd ed. London: Elsevier Academic Press; 2004. The blood group antigen facts book; pp. 29-296.

17. Lin-Chu M, Broadberry RE, Chan FJ. The blood group antigens and alloantibodies among Chinese in Taiwan. Transfusion. 1988;28:350-52.

18. Joshi S, Vasantha K. A profile of rare bloods in India and its impact in blood transfusion service. Asian J Transfus Sci 2012; 6: 42-3.

19. Reesink H, Engelfriet C, Schennach H, et al. Donors with a rare pheno [geno] type. Vox Sang 2008; 95: 236-53. 